\title{
Editorial management: innovations and perspectives
}

\author{
Maria Helena Palucci Marziale
}

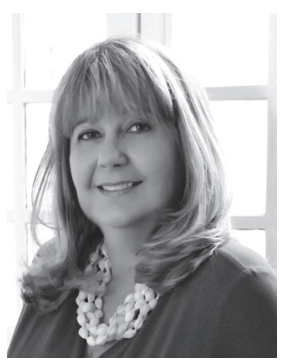

The dissemination of research results in widespread scientific journals is vital for the effective completion of the scientific communication cycle and for the enhancement of knowledge production or the use of existing knowledge. The visibility of a journal is considered as the degree of exposure of the articles in the scientific community, thus increasing the opportunities that the published material will be retrieved, read and cited, and that the scientific knowledge will be appropriate.

The quality of the papers published, their availability on the web, in full text and open access, the indexation in Brazilian and international databases, including the ability to respond to bibliographic search and control mechanisms and the journal's good performance in the rankings and measures are aspects that enhance the visibility and prestige of a scientific journal(1).

In the attempt to further its international visibility, RLAE starts 2014 with considerable changes in its editorial management, presented next.

Increase in the number of associate editors - the Editorial Committee will consist of one Scientific Editorin-Chief (ECC), one Scientific Editor (EC) and nine Associate Editors (EA), two of whom are affiliated with foreign research institutions, one from the United States and one from Canada.

Adoption of international guidelines for manuscript elaboration - to improve the quality of the information contained in the articles it publishes and reduce the processing time between submission and publication, the journal has adopted guidelines for the elaboration of manuscripts deriving from randomized controlled studies (CONSORT - http://www.consort-statement.org/), systematic reviews and meta-analyses (PRISMA - http:// prisma-statement.org/), observational studies in epidemiology (STROBE - http://strobe-statement.org/) and qualitative studies (COREQ - http://intqhc.oxfordjournals.org/content/19/6/349.long). These guidelines consist of checklists and flow charts, indicated in international declarations, and should be used by the authors to submit their manuscripts. It should be highlighted that the use of these guidelines furthers the inclusion of important information from the study in the text, enhancing the possibility that the paper will be published.

Updating of publication standards - clearer description of the adopted editorial policy, of the information made available to the authors regarding the composition of the abstract, new form of tables and figures, increased number of references cited in the articles and adjustments in the controlled vocabulary.

Adoption of the ScholarOne System - as from January 20th 2014, the authors have started using the ScholarOne System - Thomson Reuters to submit their manuscripts, which permits the management and online operation, in English, of the manuscript submission and review process. SciELO encouraged the journals in its collection to adopt the system through technical support, ranging from staff training to the implementation of the system. To operate the system, RLAE adjusted the manuscript submission forms and the assessment 
flow. After the author has submitted the manuscript, the secretariat assesses its compliance with the publication standards and, in case of a positive evaluation, the manuscript receives a protocol number and is forwarded to the ECC or, in case of any impediment, to the EC, who will pre-analyze the material received, taking into account the scope of the journal, the quality, originality of the article and contributions to the advancement of the presented knowledge. In this phase of the assessment process, the text can be refused or approved for continuation. Next, the ECC forwards the paper to an associate editor, who indicates three consultants for the peer review process. In view of the consultants' opinions, the EA issues an opinion accepting, rejecting or demanding a revision of the manuscript and forwards it to the ECC together with the consultants' opinions. After a global evaluation of the material, the ECC takes the final decision to accept, reject or review the manuscript. In case a revision is indicated, the manuscript returns to the author, and then to the consultants, EA and ECC, repeating the previous cycle. When accepted, the manuscript goes through grammatical correction and translations for publication in Portuguese, English and Spanish, followed by desktop publishing and marking.

Articles submitted until December 2013 will continue being processed in the former system until the end of their assessment process.

Adoption of PubMED Central method for article marking - offers better resolution, higher quality of images and expanded remote access to the journal.

Enhancement of the image of RLAE in social media - dissemination of news in different interactive information sources (hypertextuality) and maintenance of press releases.

These strategies have been adopted to enhance the submission and assessment process of the articles, the improve the quality of the material published, to increase the visibility of the scientific production in Ibero-American Nurses and to arouse greater attention to RLAE among international readers and authors.

\section{References}

1. Lana FCF, Marziale MHP, Caló LN. Revistas científicas da área de Enfermagem na América Latina e Caribe. In: Mucheroni ML, Ramo LMSVC, Funaro VMBO, Taruhn R, organizadores. Revistas científicas em Ciências da Saúde: visibilidade, forma e conteúdo. São Paulo: Faculdade de Saúde Pública da Universidade de São Paulo; 2013. p.11324. Disponivel em: http://www.bvs-sp.fsp.usp.br/tecom/docs/2013/muc2013001.pdf

Maria Helena Palucci Marziale is Chief Scientific Editor of the Revista Latino-Americana de Enfermagem and Full Professor of the, Escola de Enfermagem de Ribeirão Preto, Universidade de São Paulo, WHO Collaborating Centre for Nursing Research Development, SP, Brazil, marziale@eerp.usp.br

Copyright (c) 2014 Revista Latino-Americana de Enfermagem This is an Open Access article distributed under the terms of the Creative Commons Attribution Non-Commercial License (CC BY-NC).

This license lets others distribute, remix, tweak, and build upon your work non-commercially, and although their new works must also acknowledge you and be non-commercial, they don't have to license their derivative works on the same terms. 